\title{
Computers in Medicine
}

\section{A simple system for references and reprints}

\author{
A S HENDERSON, R BOSLY-CRAFT
}

\begin{abstract}
Because a personal index system for published reports is so useful in clinical research, it is well worth while setting this up on cards. If the collection is likely to exceed about 200 entries, there are now distinct advantages in also having it on a computer file. Using the simple system described here, one can then carry out very rapid searches within one's collection and can prepare error free reference lists for publications.
\end{abstract}

\section{Introduction}

Many clinicians and research workers find it useful to maintain a personal collection of references and reprints. A range of idiosyncratic practices has evolved for filing and retrieving entries. Among these, the coordinate index system originally developed by Broadhurst, ${ }^{1}$ and described in some detail by de Alarcon ${ }^{2} 14$ years ago, has been among the most widely adopted. It enables the user to inspect lists of accession numbers for all references held on a given theme or by a particular author. One of us (ASH), while maintaining a coordinate index system for 20 years, has found it expensive in the time required for entering references by author and subject headings. But the most important limitation is the size of the collection. A few hundred references can be comfortably handled using index cards, but the system becomes increasingly cumbersome thereafter. It is here that a computer can very easily be used to store the collection, conduct systematic searches within it, and produce lists of references in hard copy and in a specified house style. While the use of microprocessors for this purpose is burgeoning ${ }^{34}$ we are not aware of the existence of a suitable system for the mainframe computers common in research environments. We describe here our experience in setting up a collection using a mainframe computer and in using a program we devised for handling our collection. The method is strongly recommended both to those who already have a collection but find it a burden to maintain and to younger workers who are intending to estat lish one.

\section{Method}

There are seven steps in the use of the system: $(a)$ spotting a reference you wish to have in your collection; $(b)$ allocating an accession

\footnotetext{
NH and MRC Social Psychiatry Research Unit, The Australian National University, Canberra, ACT 2600

A S HENDERSON, MD, FRACP, director

R BOSLY-CRAFT, BSC, programmer

Correspondence to: Dr A S Henderson.
}

number; (c) selecting key words for that reference; $(d)$ physically filing the reprint or photocopy; $(e)$ entering the reference in standard format on the computer file; $(f)$ searching the collection for a specific reference or for all references held on a topic or by a particula author; and $(g)$ obtaining printout of that list in a chosen house style.

There is a great latitude in the criteria to be adopted in choosing a reference for entry. The user gains experience in how selective one should be, according to the purpose in hand. The reference is then given an accession number. We use four digits, starting with 0001 A prefix to the number is used to identify the following: $J$ : a journal $\mathrm{B}$ : a book; $\mathrm{T}$ : a thesis; $\mathrm{M}$ : an unpublished manuscript. If a reprin or photocopy is held, or the book is in the user's library, a suffix R is added. A typical accession number might then be J2153R.

Key words-Attention to the choice of these is essential for the success of the system because they are the only route by which efficien retrieval can be achieved. The overriding principle is consistency in the choice of terms and the avoidance of synonyms. The keywords should not be too general, because that will generate many irrelevant references; but they should not be too fine grained either because that will inevitably lead to undesirable omissions in later searches. We have found it desirable to increase the level of specification as one's activity in a specialty increases. This can easily be done retrospectively for references already held.

Filing the reprint or photocopy-It is convenient to write the accession number boldly on a corner of the reprint so that it can readily be identified in a filing cabinet. The reprints are then filed in batches of 10 per section for easy retrieval.

Entering the reference-When the system is first being established a new computer file is set up, into which all the user's references will be entered for many years ahead. The limitation on the number of references which may be stored is the availability of storage space on the computer system. Our current main reference file contains 4000 references, occupying 83 disc tracks on a Univac $1100 / 82$ system, where the prescribed limit per user is 200 tracks.

The reference takes the following format conforming to the Harvard style. For a journal reference, an example is:

J3404R HARRIS, R. (1982) Genetics of Alzheimer's

disease./British Medical fournal, 284, 1065-1066.

$\$$ DEMENTIA/ALZHEIMER'S DISEASE/GENETICS/

NEUROPATHOLOGY/NEUROCHEMISTRY =

For a book reference:

SCHLESSELMAN, J.J. (1982) Case-control studies./

Oxford University Press, New York. \$

EPIDEMIOLOGY/ CASE-CONTROL STUDIES =

The $\mathrm{J}$ in the accession number indicates that it is a journal reference and $\mathrm{R}$ that a reprint copy is held by the user. The slash (I) marks the end of the title. The $\$$ sign shows the end of the reference and the beginning of the keywords. The latter are separated by slash signs. The end of the entry is marked by an equals sign. These delimiters are included to enable the various segments of the entry to be recognised by the computer when it is asked to retrieve references and print them in a specified format. The user should choose which style he wishes when setting up the collection. The main options are the Harvard or Vancouver styles, but unfortunately there are many variants required by different journals. In the entry, the authors and keywords are in capitals. This ensures that searches for an author or topic can be made without creating problems when a computer distinguishes between upper and lower case. Most users will find it best to enter references in batches, say once a week. Where resources allow, it can readily be done by one's secretary.

In addition to the computer entry, it is useful to make out a reference 
card for each entry and file these in numerical sequence. This is an optional extra for users who would prefer to have hard copy of their references physically in their office. An obvious alternative, of course, is to have an up to date printout of the collection by one's desk.

Retrieval-This is where the system is a joy to use and proves to be so useful. There are two types of search that can be conducted. In the first, the user wants to refer to a particular publication, identified in the course of work or discussion. He can recall either the author or appropriate key words. At the terminal he calls up his personal reference file and gives a search command for that author or keyword. The first lines of relevant references come onto the screen. He notes the accession number of the reference he wants and takes it out of his filing cabinet.

The second type of search is on a much larger scale, where a comprehensive bibliography has to be compiled, such as a reading list for teaching or the references for a paper in preparation. In the latter, the list may be a long one and the format required by the journal may differ from that in one's system. Furthermore, the list may have to be alphabetical or in order of appearance in the text.

\section{The computer program}

For the tasks involved in storing and handling references, we have developed a Fortran 77 computer program, SPRUREF after the initials of our unit. The SPRUREF system consists of a suite of three direct access data files. The main one contains the full set of references, assigned consecutive numbers by SPRUREF as they are added. This is cross referenced to the other two files, both of which contain listings of author/s and year of publication of all references. One of these is in entry order, the other alphabetical by author.

The SPRUREF program enables one to add new references, correct or delete existing references, and print out selected reference lists using a specified format. At present we are developing edit routines to search by keyword, author, and other fields. Searches are currently conducted using the very rapid Univac file editor.

\section{Advantages and disadvantages}

In early 1982 we converted the reference collection of one of us (ASH) from the traditional coordinate system to a computer file, then went ahead with the development of the SPRUREF program. Several advantages have emerged during a year of experience with the system. The accuracy of the references is as good as the original entry, there being no possibility of subsequent typographical errors, as inevitably happens when references are transcribed from cards or other sources. Retrieval of a reference is very rapid, either on the screen or in hard copy. The system has a very large capacity, being capable of holding many thousand references and of scanning them within seconds. The file is portable between centres if the user moves jobs or if he wishes to lend a colleague a copy of his collection on a magnetic tape. There is also the potential for linkage with colleagues' systems in the same institution, a facility we now regularly invoke when conducting a search of published reports in a specialised area. Finally, it is a simple matter to keep a separate copy of the file at home on a tape, in case of fire or other loss.

We are aware of only two disadvantages, each fairly minor. Firstly, the system does require time to be spent in entering new references. This takes about four minutes a reference, including filing the reprint or photocopy. Secondly, in modifying the reference style to conform to some journals, the abbreviations used for journal titles vary greatly. The necessary changes have to be made using the computer's editor at the terminal before one has an acceptable list to send with a manuscript being submitted.

The system has proved very useful. We recommend it to any clinician or research worker who wants to reduce the drudgery of keeping a personal information system.

The authors will forward on request a listing of the program SPRUREF.

\section{References}

1 Broadhurst PL. Coordinate indexing: a bibliographic aid. Am Psychol $1962 ; 17: 149-53$.

2 De Alarcon R. A personal medical reference index. Lancet 1969;i:301-5.

${ }^{3}$ Hutton SS, Hutton SR. Microcomputer data base management of bibliographic information. Sociol Methods Res $1981 ; 9: 461-72$.

"Garfield E. Introducing "Sci-Mate"-a menu-driven microcomputer software package for online and offline information retrieval. Part 1: "The sci-mate personal data manager." Current Contents 1983;12:5-12.

(Accepted 31 August 1983)
What orthopaedic problems might be expected in a young man who jogs regularly?

Regular low milage, low speed jogging is remarkably safe. Well constructed running shoes of comfortable fit must be used to protect the foot from sone of the inevitable surface impact. Softer surfaces lead to fewer injuries than the usual roads, and it is important to start slowly with limited milage and to work up the dose of running gradually. The risk of injury increases in relation to milage run, hardness of surface, and rate of increase of training intensity. ${ }^{1}$ Underlying anatomical factors predispose to injury, including forefoot and rearfoot variations, tibial varus, genu valgum or varus, femoral torsion, and, most importantly, limb length discrepancy. The latter is widely disregarded in conventional teaching but recent studies indicate correlation between leg length differences of only a few millimetres (measured by standardised posture, low dose radiography) and injuries, particularly to the longer leg. Leg length difference is associated with stride length discrepancy and asymmetrical low back and pelvic movements. Runners often suffer back ache, pelvic and hip pain, and pain in the upper thigh, buttock, and peritrochanteric lesions. Stress fractures are widely recognised in running, ${ }^{2}$ more commonly in the lower tibia or fibula and metatarsals but more rarely in the calcaneum, femoral neck, pubic ramus, (controversially) in the pars interarticularis. The ubiquitous "runner's knee" is the commonest lesion seen in longer distance slower pace runners and is predisposed to by the anatomical malalignments outlined above as well as the slightly bent knee action of the slower paced runner, in contrast to the sprinter's vigorously and fully extended straight knee posture, which tends to protect him against this syndrome, perhaps better described as "anterior knee pain syndrome" as several soft tissue pathologies "as well as the time honoured 'chondromalacia patellae." "Soreness of the shin and calf and pain in the Achilles tendon and foot are all frequently seen in runners. Abnormal patterns of shoe wear often give vital clues to the importance of the anatomical features of running style in relation to the runner's injury. ${ }^{3}$ -PETER N SPERRYN, consultant (physical medicine and rheumatology), Uxbridge, Middx.

' Clement DB, Taunton JE, Smart GW, McNicol KL. A survey of overuse running injuries. Physician and Sports Medicine 1981;9:47-58.

Devas MB. Stress fractures in athletes. Proc R Soc Med 1969;62:932.

${ }^{3}$ Sperryn PN. Sport and medicine. London: Butterworth, 1983:227-44.

When is it necessary to sterilise hospital library books and how best is it done?

There is little evidence to support the concept of transfer of infectious agents on books. Ideally, books should be protected in a plastic cover that can be wiped over. There are two circumstances under which it might be considered prudent to sterilise library books. Firstly, where patients are suffering from highly transmissible infections, or infections where the mode of transmission is unknown or uncertain, and, secondly, where patients are being nursed in strict protective isolation -for example, for a bone marrow transplant. In practice, library books are best not issued to either category of patient because they cannot be effectively decontaminated without damage. The only method of sterilisation likely to be effective is controlled exposure to ethylene oxide. To ensure penetration of gas, however, the book would need to be stood on end and fanned open. If a book inadvertently came into contact with a patient in the first category above I would incinerate it.-G L RIDGWAY, consultant microbiologist, London. 